\title{
NUCLEAR ENERGY RESEARCH INITLATIVE \\ DEVELOPMENT OF A STABILIZED LIGHT WATER REACTOR FUEL MATRIX FOR EXTENDED BURNUP
}

Phase 1 Annual Report

Proposal Number 99-0197

Pacific Northwest National Laboratory

B. D. Hanson, Principal Investigator

J. Abrefah

S. C. Marschman

University of California, Berkeley

S. G. Prussin

September 1,2000

Prepared for:

U.S. Department of Energy

Oakland Operations Office

1301 Clay Street

Oakland, CA 94612

Attn: Salma El-Safwany, NSPD

U.S. Department of Energy

Office of Nuclear Energy, Science and Technology

19901 Germantown Road

Germantown, MD 20874

Attn: Frank Ross, NE-20

Pacific Northwest National Laboratory

Richland, WA 99352 


\section{DISCLAIMER}

This report was prepared as an account of work sponsored by an agency of the United States Government. Neither the United States Government nor any agency thereof, nor any of their employees, make any warranty, express or implied, or assumes any legal liability or responsibility for the accuracy, completeness, or usefulness of any information, apparatus, product, or process disclosed, or represents that its use would not infringe privately owned rights. Reference herein to any specific commercial product, process, or service by trade name, trademark, manufacturer, or otherwise does not necessarily constitute or imply its endorsement, recommendation, or favoring by the United States Government or any agency thereof. The views and opinions of authors expressed herein do not necessarily state or reflect those of the United States Government or any agency thereof. 


\section{DISCLAIMER}

Portions of this document may be illegible in electronic image products. Images are produced from the best available original document. 


\section{Summary}

\section{Objective}

The main objective of this project is to develop an advanced fuel matrix capable of achieving extended burnup while improving safety margins and reliability for present operations. In the course of this project, we will improve understanding of the mechanism for high burnup structure (HBS) formation and attempt to design a fuel to minimize its formation. The use of soluble dopants in the $\mathrm{UO}_{2}$ matrix to stabilize the matrix and minimize fuel-side corrosion of the cladding is the main focus.

\section{Approach}

This project will be accomplished in three phases over a 3-year period as documented in proposal 99-0197. The work has been divided into three main tasks, with the work in each being performed in parallel for active feedback between the experimental and modeling efforts.

\section{Phase I Accomplishments}

\section{Task 1: Understand and Model HBS Formation}

During Phase $\mathrm{I}$, this task focused on performing a comprehensive literature review to guide the future efforts. Five different high burnup fuels, including two MOX fuels, were sectioned and prepared for examination of the HBS. Atomic force microscopy (AFM) has been used and appears to be able to map the HBS as a function of radius. We believe we are the first to use an AFM successfully on such highly radioactive samples. A scanning electron microscope (SEM) and X-ray diffractometer (XRD) were both readied for examination of these spent fuel samples.

Modifications to the RABURN (Resonance Absorption Burnup) model have been made to incorporate true cylindrical geometry. Temperature- and burnup-dependent thermal conductivities have been calculated and a module to incorporate them and a more accurate radial temperature distribution is being developed. A more realistic flux model is also being incorporated. RABURN will then be benchmarked against experimental data to be derived during Phase II, as well as against other, more complex neutronics codes.

\section{Task II: Develop Matrix Stabilization Model}

Significant efforts went into preparing the SEM and XRD units for testing of the spent fuels and candidate fuels. The SEM is now fully operational and we are simply waiting for our turn in the queue. The detector system for the XRD is expected to be repaired and returned early in Phase $\Pi$. The measurement of lattice parameters and radionuclide content is a function of radius is crucial to refinement of the matrix stabilization model. 
As part of this task, spent fuel samples were to be oxidized as part of the Yucca Mountain Project (YMP) and then dissolved and analyzed for radionuclide content. Delays in the YMP work have resulted in a subsequent 6 -month delay in the NERI work. Oxidation tests have resumed and we anticipate being able to accelerate some of the tests to get back on schedule.

All of the necessary paperwork to adhere to administrative regulations governing the use of fuel enriched in ${ }^{238} \mathrm{U}$ has been completed. Commercial fuels have now been ordered for use in the oxidation studies.

\section{Task III: Design and Test Advanced Fuel Matrix}

An extensive literature review on the effect of dopants on the $\mathrm{UO}_{2}$ lattice has been performed to guide the fuel design efforts. A summary report will be issued soon.

All of the equipment necessary to fabricate pellets based on the "recipes" of dopants developed in the other two tasks has been purchased. Most items, including the high temperature tube furnace (for grain growth experiments and sintering of pellets) and the pellet press, have been installed.

Commercial samples of gadolinia-doped fuels have been ordered for use in baseline tests of physical and chemical properties. The fuels developed for this project will be compared against these baselines.

Discussions with Argonne National Laboratory on the use of their Advanced Photon Source or Transmission Electron Microscopy facilities to determine the location of dopants in the fuel matrix have been initiated.

\section{Project Management/Financial Status}

All of the primary deliverables for Phase I have been met. We have identified the means of getting back on schedule for almost all Phase II deliverables, assuming that funding arrives as scheduled. We request a 6-month extension of Phase I funding and activities to meet the objectives and deliverables for Phase II. In addition, we request a 6-month extension on the delivery of the Matrix Stabilization and HBS Model Report. All other deliverables are currently on schedule. 


\section{Contents}

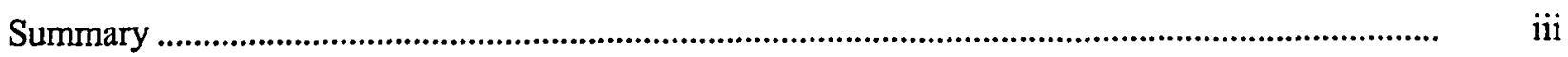

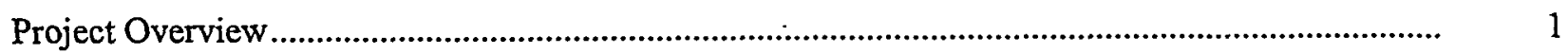

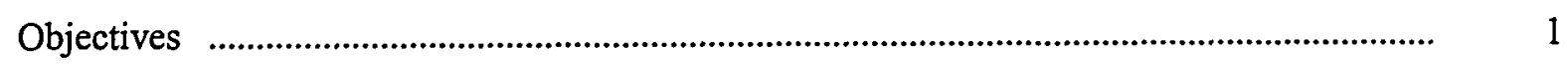

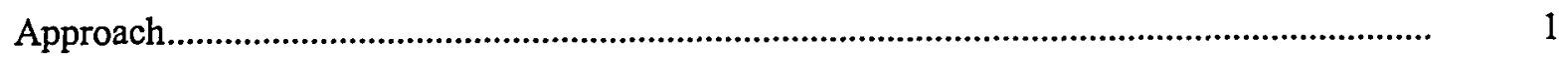

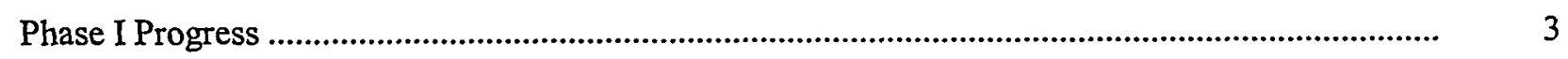

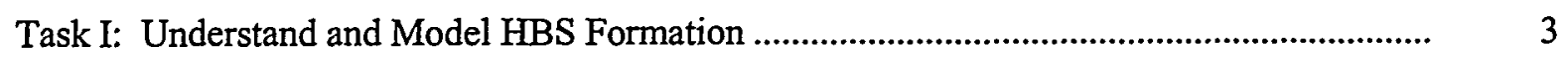

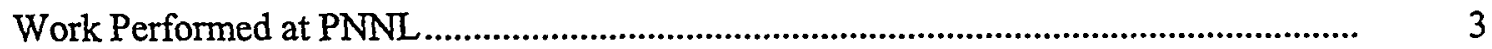

Work Performed at UCB ...................................................................................

Task II: Develop Matrix Stabilization Model .................................................................. 7

Task III: Design and Test Advanced Fuel Matrix................................................................. 8

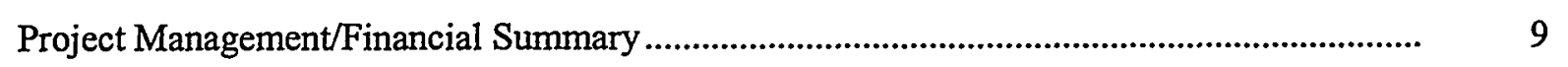




\section{Figures}

1 Photograph of the Park Scientific Instruments Autoprobe LS Atomic Force Microscope in a Shielded Glovebox at PNNL

2 AFM Image of Unirradiated $\mathrm{UO}_{2}$ Showing the Grain Structure........................................ 15

$3 \quad$ AFM Image of LWR Spent Fuel Away From the Restructured Zone .................................. 16

$4 \quad$ AFM Image of LWR Spend Fuel in the Restructured Zone ................................................. 16

$5 \quad$ AFM Image at Higher Resolution Showing Restructured Grains....................................... 17

$6 \quad 1700^{\circ} \mathrm{C}$ Tube Furnace for Grain Growth and Sintering Experiments ................................... 17

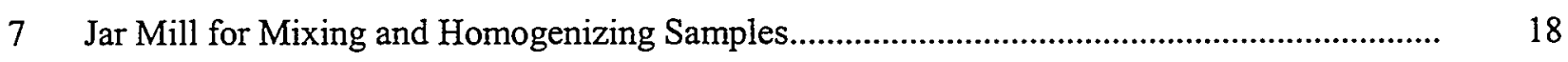

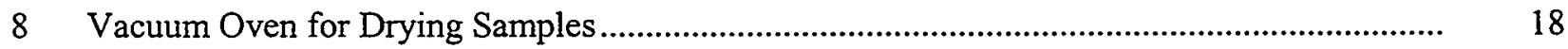

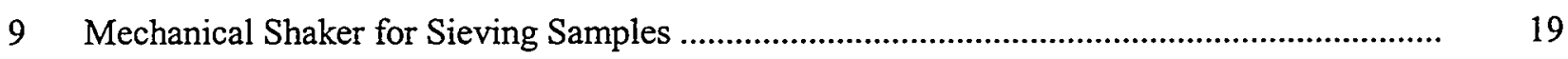

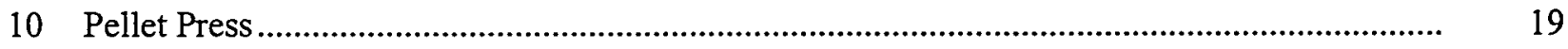

11 Low Speed ISOMET ${ }^{\mathrm{TM}}$ Saw for Sectioning Samples for Analysis ..................................... 20 


\section{Project Overview}

\section{Objectives}

The main objective of this project is to develop an advanced fuel matrix based on the currently licensed $\mathrm{UO}_{2}$ structure capable of achieving extended burnup while improving safety margins and reliability for present operations. Bumup is currently limited by the fission gas release and associated increase in fuel rod internal pressure, fuel swelling, and by cladding degradation. Once fuels exceed a threshold burnup, a "rim" or high burnup structure (HBS) forms. The HBS is characterized by the development of a subgrain microstructure having high porosity and low thermal conductivity. It is believed that the lower thermal conductivity results in larger temperature gradients and contributes to subsequent fission gas release. Fuel designs that decrease the centerline temperature while limiting the HBS restructuring, thereby decreasing the fission gas release, should be able to achieve higher burnup and even allow higher operating power for increased efficiency.

Research at Pacific Northwest National Laboratory (PNNL) has demonstrated that the soluble fission products and actinides present in the matrix of irradiated (spent) fuels stabilize the fuel matrix with respect to oxidation to $\mathrm{U}_{3} \mathrm{O}_{8}$. The higher the soluble dopant concentration, the more resistant the fuel has been to undergoing the restructuring of the matrix from the cubic phase of $\mathrm{UO}_{2}$ to the orthorhombic $\mathrm{U}_{3} \mathrm{O}_{8}$ phase. In this project, we are attempting to utilize the changes in fuel chemistry that result from doping the fuel to design a fuel that minimizes HBS formation. The use of dopants that can act as getters of free oxygen and fission products to minimize fuel-side corrosion of the cladding is also being studied.

In addition to the use of dopants, we are studying techniques such as the use of large grain sizes and radial variations in enrichment to minimize HBS formation and fission gas release. In this project, we are using a combination of modeling and experimental studies to determine the optimum design.

\section{Approach}

This project will be accomplished in three phases over a 3-year period as documented in proposal 99-0197. The work has been divided into three main tasks, with the work in each being performed in parallel so there will be active feedback between the experimental and modeling efforts. Each task spans all or portions of the three phases. The schedule is meant to be somewhat fluid to allow iterations and change of emphasis as new knowledge is obtained. A summary of the results of completed work, work in progress, and the path forward for each of the tasks in Phase I follows. 


\section{.}




\section{Phase I Progress}

\section{Task I: Understand and Model HBS Formation}

The formation of the HBS is one reason that the Nuclear Regulatory Commission (NRC) has imposed a burnup limit of about $62 \mathrm{GWd} / \mathrm{t}$ on present light water reactor (LWR) fuels. One of the primary driving forces behind the HBS formation is the significantly higher burnup experienced by the approximately $200 \mu \mathrm{m}$ to $300 \mu \mathrm{m}$ pellet periphery. This increased burnup is a result of the intense resonance absorption in ${ }^{238} \mathrm{U}$ that leads to a significant gradient in the radial distribution of plutonium $(\mathrm{Pu})$ near the surface. The buildup of $\mathrm{Pu}$ results in corresponding gradients in fission rates and the concentrations of fission products and higher actinides.

\section{Work Performed at PNNL}

As outlined in NERI proposal 99-0197, there are significant unresolved issues in understanding how and why the HBS forms. John Abrefah and Brady Hanson, both working on this project for PNNL, attended the Light Water Reactor Fuel Performance Meeting in April 2000. There were many papers relating to HBS presented at the conference, but again, there is substantial disagreement as to the mechanism and even properties (e.g., thermal conductivity) of the HBS. The PNNL staff met with Motoyasu Kinoshita and Hans Matzke, the two lead investigators of the international High Burnup Rim Project. An agreement was reached to share all nonproprietary data and to have a free flow of ideas to help each of the projects.

An extensive literature review of HBS formation has been conducted. Again, there is significant disagreement in the scientific community about the mechanism for HBS formation and the effect of the "rim" once it is formed. A summary report of this literature review is in its final stages and soon will be published as a PNNL report. It is clear from this review that an easy and fast technique for mapping out the radial distribution of the HBS and the ability to observe the interface between the restructured and original fuel would be beneficial. Motoyasu Kinoshita and Hans Matzke agreed that atomic force microscopy (AFM) should provide the ability to perform these tasks as long as the resolution could overcome the gross morphology of the fuel surface.

At PNNL, we have three different segments of ATM-109 fuel, each with a burnup in the range of $60 \mathrm{GWd} / \mathrm{t}$ to $75 \mathrm{GWd} / \mathrm{t}$. The fuels have different initial enrichments that affected the temperature profile experienced by each fuel during reactor service, and one had an initial doping of gadolinia to serve as a burnable poison. We also had available two different MOX fuels with burnups in excess of $100 \mathrm{GWd} / \mathrm{t}$. Using a slow-speed ISOMET ${ }^{\mathrm{TM}}$ saw, one to three thin disks approximately $1 \mathrm{~mm}$ thick of each of these five fuels were cut in the PNNL- hot cells. Since we were interested in examining these specimens using AFM, scanning electron microscopy (SEM), and optical microscopy (ceramography), the fuels had to be cut without using any resins to bind the fuel. In most cases, the majority of the fuel remained intact 
within the cladding. A similar technique was tried on a lower burnup ATM-106 segment, where formation of the HBS was just beginning. Because the fuel was not well bound to the cladding, all of the fuel fell out as the segment was cut.

The first two attempts at preparing mounts for the AFM examination were not as successful as we would have liked. Because of radiation dose constraints, the entire cut segment of fuel could not be examined. We attempted to remove about half of the fuel from the disk, which would leave behind the cladding and half of the fuel. That would allow a very accurate radial mapping of the HBS and the interfaces between the fuel and cladding as well as the restructured/nonrestructured zone. In both cases, almost all fuel fell out of the cladding. One fragment was then mounted on a steel disk for examination to determine if the HBS could be observed before changing our mounting technique.

A fragment of ATM-109 fuel was examined using the Park Scientific Instruments Autoprobe LS (see Figure 1) located in a shielded glovebox at PNNL. Various points along the perimeter of the fragment were examined. A fragment of unirradiated $\mathrm{UO}_{2}$ was also examined for comparison. Those areas far from the original pellet surface were found to have a surface morphology similar to the unirradiated $\mathrm{UO}_{2}$ (see Figures 2 and 3). A scan of the fragment near the original clad interface using the same resolution clearly shows a different structure (see Figure 4). Using a much higher resolution, the detailed grain structure around and inside pores can clearly be identified (see Figure 5). The grain sizes observed using AFM range between $0.15 \mu \mathrm{m}$ and $0.35 \mu \mathrm{m}$, the same as reported in literature when using either SEM or transmission electron microscopy (TEM). Most often, the SEM observations of restructuring require high magnification within a pore. The AFM seems to be able to identify the restructuring throughout the matrix. Confirmatory tests will be performed using SEM, but we are confident that AFM will provide a very useful technique for quickly mapping out the radial distribution of the HBS. This information is vital to the modeling efforts, especially in determining just how large the restructured area is and where it was located in the fuel.

We will attempt mounting the cut segments of fuel on the steel disk prior to removing fuel. That should allow a full radius to be available for examination. After examination by AFM, the sample will undergo a similar radial mapping using SEM. In addition to mapping the HBS, a shielded SEM with energy-dispersive $\mathrm{x}$-ray analysis for use on highly radioactive samples can determine the radionuclide concentration of various elements as a function of radius. This information, in conjunction with radiochemical analyses on portions of dissolved spent fuel (to be performed in the first quarter of Phase II), will be used to further benchmark the RABURN (Resonance Absorption Burnup) model being worked on at the University of California at Berkeley (UCB). The SEM examinations were originally scheduled to occur during Phase I. However, the SEM was not operational for much of Phase I and the project that purchased the equipment has priority in running samples. A 6-month extension of Phase I has been requested and the SEM examination will be performed within that time frame.

One hypothesis found in literature for the mechanism of HBS formation is that the accumulation of fission-induced damage, i.e., dislocation networks, organize into subgrains which form the nuclei for recrystallization. To help determine if that or the lattice contraction due to the doping effect is the mechanism for HBS formation, $\mathrm{x}$-ray diffraction (XRD) of the spent fuel samples and of our doped fuels will be performed. The crystalline phases will be identified and the lattice parameter measured. During 
Phase I, the XRD was tested to determine if we could readily observe the small changes in lattice parameter expected. We were having problems with the resolution of the detector, hampering this ability. The project made a substantial investment in repairing the detector system and purchasing the software used for lattice parameter measurement. The detector is to be returned, installed, and tested early in Phase II.

The primary objectives of Task I that were to be accomplished during Phase I have been met, with the exception of the SEM and XRD examination of the high burnup fuels. The problems have been identified and will be resolved, allowing these objectives to be met within the 6-month extension.

\section{Work Performed at UCB}

The one-dimensional burnup code RABURN was developed to obtain fast and reasonable estimates of the radial actinide and fission product distributions in spent fuel as a function of burnup, especially in the high-burnup rim region. It explicitly treats absorption in the most important resonances of the even, even actinides by expansions in Chebyshev polynomials. The neutron flux is taken to be a thermal flux and a 1/e epithermal flux. The radial temperature distribution is taken as a simple parabolic function with nominal values for the surface and centerline temperatures. The code uses slab geometry and approximates the radial burnup in a cylindrical fuel element by rotating the slab through an angle of $2 \pi$. To accommodate the rapid flux attenuation, the fuel is zoned with narrow zones near the slab surface and much broader zones in the interior.

Comparisons of the calculated radial distributions of uranium, plutonium, and americium with experimental data obtained at PNNL as well as the radially integrated abundances of the most important actinide isotopes were quite good. In general, the integrated isotopic abundances were quite close to those calculated with the code ORIGEN 2. In comparison to complex reactor codes coupled to ORIGEN through empirically adjusted cross sections, RABURN uses only the fundamental physics parameters of resonance absorption along with normal absorption and scattering cross sections outside the region of the resonances. Also, in comparison with such coupled codes, RABURN requires only a total of about 3.5 minutes on a $300 \mathrm{MHz}$ Power $\mathrm{PC}$ to perform a calculation with reasonable accuracy on burnups in the range of 20 to $50 \mathrm{GWd} / \mathrm{t}$.

In order to improve both the accuracy of the code and its physical assumptions, we have been engaged in efforts to incorporate real cylindrical geometry, realistic temperature distributions, and more realistic flux distributions into the code.

To incorporate true cylindrical geometry, the solution to the diffusion in cylindrical coordinates is required. Because the radius of real reactor fuel is small compared to the mean free path for interaction of even thermal neutrons, we assume that every neutron that undergoes any type of interaction is lost from the incident flux. Thus we approximate the absorption cross section by the total cross section with respect to attenuation. Further, because the mass of neutron is small compared to the mass of the elements within the fuel, we can also approximate the transport cross section by the total cross section. Thus, the solution to the continuity equation that we use is expressed in terms of the modified Bessel function of order zero. 
To implement this approximation for cylindrical geometry into RABURN, the radial zoning of a slab and its exponential absorption characteristic were replaced by a corresponding cylindrical geometry and the absorption characteristic noted above. Initial tests with the new geometry using zones of two dimensions gave results comparable to those obtained with the slab approximation but showed a troublesome discontinuity in burnup at the boundary between the different sized zones. (A similar discontinuity was seen with the slab approximation but was much less prominent.) The problem was attributed to the simple averaging approximation used in the initial coding. However, when correct averaging was coded, the problem persisted. This indicated that the problem had to be associated with the assumption of constant flux and atom density throughout a time step, notwithstanding the fact that the time steps were small compared to the time required to achieve a given burnup in the range of 25 to $60 \mathrm{GWd} / \mathrm{t}$. This was confirmed by running several tests with substantially smaller time steps. As the number of time steps increased, the discontinuity continuously decreased.

Tests were performed to compare the actinide distributions calculated with the cylindrical and slab geometries. As expected, the neutron flux in the interior of the fuel was somewhat larger with cylindrical geometry as compared to the slab geometry. Nevertheless, analysis and comparison of the computer outputs with the two geometries for the same total burnup indicated quite similar results for the majority of the important actinide isotopes of uranium, plutonium, americium, and curium.

During these tests, we compared the effect of temperature on the actinide isotope distributions with those obtained previously using slab geometry. We found very significant effects, especially on the relative abundance of the even, even and odd- $A$ (where $A$ is the atomic mass) isotopes. Variation in both the ratio of the epithermal and thermal fluxes as well as the capture-to-fission ratios of isotopes with significant errors in their resonance properties also produced significant changes. This clearly indicated the importance of a much more careful treatment of the temperature distribution within the fuel.

An extensive literature search was performed to examine data and correlations on the temperature dependence of the thermal conductivity of $\mathrm{UO}_{2}$ fuel and its burnup dependence. Reasonable correlations were found and tested to determine the likely differences that might result between use of the simple constant parabolic temperature profile and a much more realistic treatment of the thermal characteristics of the fuel. Although not necessary for general purpose calculations, the sensitivity of resonance absorption to temperature and its time variation during long-term residence in a reactor suggests that the burnup distribution in the vicinity of the high-burnup rim region of the fuel can be quite sensitive to the assumptions made. Indeed, scoping calculations indicated that a significant effect can result and indicated the importance of a more realistic treatment of the radially dependent temperature history of the fuel.

We have developed a temperature module based on a finite element approach that is designed to calculate the temperature profile as a function of burnup for each zone and time step in the entire burnup calculation. Because of the small dimension of each zone and the need to maintain a small Fourier number, a fairly small time interval is required in order for the calculation to converge with accuracy. The module itself now requires about one-fourth the time required for the complete burnup calculation with the constant temperature profile approximation. 
Currently a FORTRAN code is being written that can be incorporated directly into RABURN. In addition, we are investigating techniques to reduce the time for convergence in order to realize a reasonable computation time with widely available computers. We expect to complete this work within the next 3 months. We will then incorporate a somewhat more realistic flux model to complete the code.

This project is serving as the M.S. thesis research of a graduate student in Nuclear Engineering at Berkeley. Given the demands of our course work requirements, the project has proceeded quite well with the exception of this past summer. Due to personal issues, the student was unable to devote full time to his research and thus we are about 3 months behind where we had projected we would be at this time.

\section{Task II: Develop Matrix Stabilization Model}

As discussed in the original NERI proposal 99-0197, we believe that the resistance to oxidation to $\mathrm{U}_{3} \mathrm{O}_{8}$ as a function of burnup can be explained largely by the change in lattice energy that accompanies the change in lattice parameter. The lattice parameter is expected to exhibit a net decrease as more and more soluble fission products are incorporated into the matrix, which in turns necessitates the oxidation of uranium ions to higher valence states with smaller ionic radii. The radiochemical analyses, SEM and XRD examinations, and the use of the RABURN model described in Task I are all essential to obtaining the information to further refine and develop the matrix stabilization model.

Thermogravimetric analysis (TGA) runs to oxidize spent fuel were to have been performed during Phase I as part of an ongoing research project at PNNL in support of the Office of Civilian Radioactive Waste Management Yucca Mountain Project (YMP). These results, and the radiochemical analyses of the samples that were to be part of this NERI project, would add the additional data necessary for the model development. However, a change in priorities for YMP resulted in modeling work being performed prior to resumption of experimental work. This resulted in more than a 6-month delay in oxidizing new spent fuel samples and a corresponding delay in the matrix stabilization modeling effort. In addition, this modeling was to have been part of the $\mathrm{Ph} . \mathrm{D}$. thesis of a graduate student at UCB accepted for admission in Fall 1999. Unfortunately, the student requested delayed admission for 1 year because of personal reasons. No other student with the requisite interest and qualifications has been found. The opportunity is being extended to students in other departments to try and get this task back on schedule.

Work on TGA oxidation for YMP has now resumed. In addition, TGA is scheduled to be performed on unirradiated commercial fuels with various dopant concentrations to help serve as a baseline for our modeling and fuel fabrication efforts. The cost of obtaining fuel made from natural or depleted uranium that meets all quality assurance guidelines of the manufacturer proved prohibitive. Manufacturers add gadolinia only to serve as a burnable poison in higher enriched fuels, so they would have had to make a special small batch just for this project. Instead, we are now purchasing "off-the-shelf" pellets from Siemens Power Corporation that meet all quality assurance requirements and have the various concentrations of gadolinia that we need. We have been delayed slightly because we needed to update our Project Management Plan and do the necessary paperwork to have the lab established as a Materials Balance Area. This included having proper security locks installed to safeguard the enriched fuel that we will be receiving. These tasks have been completed so we now have laboratory permission to purchase the enriched fuel with the gadolinia doping. We expect to receive this fuel during the first quarter of 
Phase II and TGA experiments will then begin immediately. The TGA has been calibrated and the new pressure transducers installed so the system is ready for operation. This TGA will also be used to oxidize samples of the fuels we prepare as part of this project. In addition, it will be used to perform the grain growth experiments on small samples.

While this task is behind schedule, the resources of the YMP and this project are now available and we expect to make up much lost time. However, we request that the Matrix Stabilization Model and HBS report originally to be submitted March 30,2001, be postponed to September 30, 2001, to reflect the 6-month delay and extension outlined above. While the report would be delayed, it would not impact other activities because of the close communication between PNNL and UCB. Also, those performing the experiments are the same ones doing modeling efforts so a delay in the report does not hamper future activities.

\section{Task III: Design and Test Advanced Fuel Matrix}

The main objective of the overall project is to develop an advanced fuel matrix that can be utilized in present reactors to improve reliability and that can achieve extended burnup. Tasks I and II provide direct input to the design and testing to be performed in Task III. The concept of doping the $\mathrm{UO}_{2}$ matrix to achieve the desired results is the main thrust of this activity.

An extensive literature review has been performed to study the effects of dopants, such as solubility, thermal conductivities, effect on oxidation (oxygen potential), change in lattice parameter, etc. A summary report will be issued as soon as the chapter on "gettering" is complete. We are looking for dopants that will not only stabilize the matrix, but that can act as getters of free oxygen and fission products (i.e., Cs and $\mathrm{D}$ to further reduce fuel-side corrosion of the cladding. It is clear that doping concepts are nothing new. For example, the fuel for the Shippingport reactor combined $\mathrm{UO}_{2}$ and $\mathrm{ZrO}_{2}$. However, this fuel used $\mathrm{UO}_{2}$ ( 26 to $38 \mathrm{wt} \%$ ) in solid solution with $\mathrm{ZrO}_{2}$ whereas we propose using small quantities of $\mathrm{ZrO}_{2}$ in solid solution with $\mathrm{UO}_{2}$. Similar trends with thorium also exist where the thorium is the major constituent. In this project, we will utilize the knowledge of the dopants used in the past, but relating them to being minor constituents in a $\mathrm{UO}_{2}$ matrix. We believe such an approach will not only meet our objectives, but will allow relatively straightforward licensing by the NRC of such a fuel for commercial use.

One of the concepts we are also investigating is the ability of larger grain fuels to retain fission products. While much work is being done in this area, most efforts concentrate on adding diffusion enhancers to the fuel to grow the grains. Some of these elements may be detrimental to our overall efforts, so we are concentrating on growing grains by oxidizing the fuel in an oxygen-free steam atmosphere. Scoping work was performed at UCB and is now being performed at PNNL. The TGA systems used for oxidation studies (Task II) are ideally suited for these tests when small samples are used. However, it is important to verify that such a method will work on bulk, pellet size samples. A high temperature tube furnace has been purchased and installed in a fume hood to allow such experiments to be performed (see Figure 6). When the ceramic inner tube arrives, the gas connections will be made and the furnace will be fully operable. This furnace will also be utilized for sintering the bulk pellets in a 
hydrogen atmosphere at temperatures up to $1700^{\circ} \mathrm{C}$. Grain sizes will be measured before and after both the steam oxidation and the hydrogen sintering steps using both ceramography and our SEM.

Since we will need to make pellets of various "recipes," based on the optimal dopant loading determined in Tasks I and II, we needed to establish the capability of making our own pellets. Uniformity and homogeneity are of the utmost importance so that we can determine if changes in the properties measured are truly due to the dopant recipe, or from variations in pellet characteristics due to fabrication. We have purchased and installed a large jar mill (see Figure 7) so that large quantities of $\mathrm{UO}_{2}$ and dopants can be mixed to provide this homogeneity. The powders will be dried in a vacuum oven (see Figure 8) and sieved using a mechanical shaker (see Figure 9). The powders will then be loaded into a special die and pressed (see Figure 10) into pellets. The pellets will undergo the grain growth and sintering steps in the tube furnace. Various iterations of this approach will be tried to ensure uniformity in pellet fabrication. All of this work is to be performed in radiation and contamination areas. We have worked out the procedures to allow most of this work to be performed on the benchtop. Subsamples of the pellets (both made by us or obtained commercially) will be cut in a contamination area fume hood using a slow speed ISOMETTM saw (see Figure 11).

These subsamples will be tested to determine their physical and chemical properties such as density, thermal conductivity, creep, lattice parameter, and oxidation resistance. These properties will be compared against the baselines established by the fuel purchased from Siemens Power Corporation. Again, there has been a slight delay obtaining these fuels as the security issues were resolved. However, using the techniques above and by keeping the subsamples to less than accountable quantities, all testing, including in the Thermal Properties Laboratory at PNNL, can readily be accomplished. The fuel fabrication report due March 30, 2001, should still be issued on schedule.

In addition, Steve Marschman of PNNL visited the Advanced Photon Source (APS) at Argonne National Laboratory (ANL). The goal was to determine if the APS could be used to help identify the location of the dopants in the $\mathrm{UO}_{2}$ matrix to further the modeling work. While this method could be useful, the cost is prohibitive. Steve also met with Edgar Buck of ANL who suggested a collaborative effort using TEM. Edgar has since visited PNNL to determine what it would take for TEM examinations to be performed here. We are encouraged by his comments and feel confident that this will be one more key to the matrix stabilization efforts.

The literature review has been performed and the entire fuel fabrication lab is almost complete. The summary report will be issued shortly. The major deliverables for Task III associated with Phase I have been achieved. We expect to be making the first fuel pellets during the first quarter of Phase II.

\section{Project Management/Financial Summary}

As outlined previously and in the quarterly reports submitted to the Department of Energy (DOE), there was an initial 2-month delay from the time that PNNL received the funds to the time that work was allowed to resume. Those administrative issues have been resolved. In addition, there is about a 6-month delay associated with Task II because of the change in priorities for the YMP. The oxidation tests have begun again to provide the necessary information to this NERI project. A 6-month extension was 
requested from DOE-Oakland. However, we feel that we can get back on schedule within about 2 or 3 months. In the meantime, the funds for Phase II have not yet been received and thus work on Phase II deliverables has not commenced. We continue to spend Phase I funds on the work delayed as outlined above. It is anticipated that the funds remaining under Phase I will be exhausted by the end of September 2000. The accelerated spending is a result of the purchase and installation of the equipment for the pellet fabrication laboratory.

Including the cost of the equipment received by August 5, 2000 (even if the associated charges had not yet gone through the finance office), the total spent during Phase I (August 5, 1999, to August 5, 2000 ) was $\$ 175,703$ or $70 \%$ of that allocated. The funds supplied to UCB have been used to support the graduate student working on the RABURN model and for Professor Prussin's time. The Financial Status Report for Phase I work at PNNL and the current schedule follow.

Based on the discussion above, we request that the Matrix Stabilization Model and HBS report due March 30, 2001, be postponed until September 30, 2001. 
FINANCIAL STATUS REPORT

(Long Form) (Follow instructions on the back)

\begin{tabular}{|l|l|}
\hline $\begin{array}{l}\text { 1. Federal Agency and Organizational Element } \\
\text { to Which Report is Submitted } \\
\text { Oakland Operations Office }\end{array}$ & $\begin{array}{l}\text { 2. Federal Grant or Other Identifying Number Assigned } \\
\text { By Federal Agency } \\
\text { MASF990197 }\end{array}$ \\
\hline
\end{tabular}

\begin{tabular}{|l|ll|}
$\begin{array}{l}\text { OMB Approval } \\
\text { No. 0348-0039 }\end{array}$ & $\begin{array}{rr}\text { Page } 1 \text { of } 1 \\
\text { pages }\end{array}$ \\
\hline
\end{tabular}

3. Recipient Organization (Name and complete address, including ZIP code)

Battelle Memorial Institute, Pacific Northwest Division (PNNL) P.O. Box 999 Battelle Boulevard. Richland, Washington 99352

\begin{tabular}{|c|c|c|c|}
\hline $\begin{array}{l}\text { 4. Employer Identification Number } \\
31-4379427\end{array}$ & $\begin{array}{l}\text { 5. Recipient Account Number or Identifying Number } \\
31242\end{array}$ & $\begin{array}{l}\text { 6. Final Report } \\
\square \text { Yes } \square \text { No }\end{array}$ & $\begin{array}{l}\text { 7. Basis } \\
\square] \text { Cash } \square \text { Accrual }\end{array}$ \\
\hline $\begin{array}{l}\text { 8. Funding/Grant Period (See instructions) } \\
\text { From: (Month, Day, Year) } \\
\text { Anoust ? } 1990\end{array}$ & $\begin{array}{l}\text { To: (Month, Day, Year) } \\
\text { Inlv } 31 \text { 20n? }\end{array}$ & $\begin{array}{l}\text { this Report } \\
\text { ay, Year) }\end{array}$ & h, Day, Year) \\
\hline
\end{tabular}

InIlv 31 20n?

10. Transactions:

Anoust ? 1099

\begin{tabular}{|l|}
\hline a. Total outlays \\
\hline b. Refunds, rebates, etc. \\
\hline c. Program income used in accordance with the deduction altermative \\
\hline d. Net outlays (Line $a$, less the sum of lines $b$ and $c$ ) \\
\hline
\end{tabular}

\begin{tabular}{|c|l|l}
\hline $\begin{array}{c}\text { I } \\
\text { Previouslv Reported }\end{array}$ & $\begin{array}{c}\text { II } \\
\text { This Period }\end{array}$ & $\begin{array}{l}\text { III } \\
\text { Cumulative }\end{array}$ \\
\hline$\$ 0$ & $\$ 175,703$ & $\$ 175,703$
\end{tabular}

Recipient's share of net outlays, consisting of:

e. Third party (in-kind) contributions

f. Other Federal awards authorized to be used to match this award

g. Program income used in accordance with the matching or cost

sharing altemative

h. All other recipient outlays not shown on lines $e$, for $g$

i. Total recipient share of net outlays (Sum of lines, e, f, $g$ and $h$ )

j. Federal share of net outlays (line $d$ less line $i$ )

k. Total unliquidated obligations

I. Recipient's share of unliquidated obligations

m. Federal share of unliquidated obligations

n. Total federal share (sum of lines $\mathrm{j}$ and $\mathrm{m}$ )

o. Total federal funds authorized for this funding period

p. Unobligated balance of federal funds (Line o minus line $n$ )

\begin{tabular}{|c|c|c|c|c|c|}
\hline \multicolumn{3}{|c|}{$\begin{array}{l}\text { Program income, consisting of: } \\
\text { a. Disbursed program income shown on lines } c \text { and/or } a \text { above }\end{array}$} & 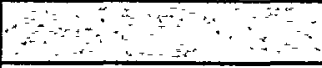 & $\therefore \quad \therefore$ & \\
\hline \multicolumn{3}{|c|}{ T. Disbursed program income using the addition alternative } & 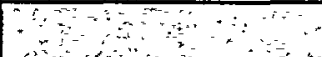 & $\therefore \quad \therefore$ & \\
\hline \multicolumn{3}{|c|}{ s. Undisbursed program income } & 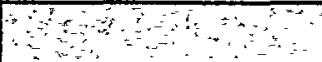 & 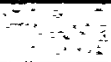 & \\
\hline \multicolumn{3}{|c|}{ t. Total program income realized (Sum of lines $q, r$ and $s$ ) } & & & \\
\hline \multirow{2}{*}{$\begin{array}{l}\text { 11. Indirect } \\
\text { Expense }\end{array}$} & $\begin{array}{r}\text { a. Type of Rate (Place "X" in } \\
\square \text { Provisional } \\
\end{array}$ & $\begin{array}{l}\text { box) } \\
\text { Predetermined }\end{array}$ & 므 Final & & \\
\hline & $\begin{array}{l}\text { b. Rate } \\
\text { Various }\end{array}$ & $\begin{array}{l}\text { c. Base } \\
\text { Various }\end{array}$ & $\begin{array}{l}\text { d. Total Amount } \\
\$ 74,361\end{array}$ & $\begin{array}{l}\text { e. Federal } \\
\$ 74,361\end{array}$ & \\
\hline
\end{tabular}

12. Remarks: Attach any explanations deemed necessary or information required by Federal sponsoring agency in compliance with governing legislation:

$\begin{aligned} & \text { 13. Certification: I certify to the best of my knowledge and belief that this report is correct and complete and that all outlays and unliquidated obligations } \\
& \text { are for the purpose set forth in the award documents. }\end{aligned}$
\begin{tabular}{|l|l}
\hline Typed or Printed Name and Title & Telephone (Area code, number and extension) \\
\hline Signature of Authorized Certifying Official & Date Report Submitted \\
\hline $\begin{array}{l}\text { Previous Edition Usable } \\
\text { NSN 7540-01-012-4285 }\end{array}$ & 269-104 Prescribed by OMB Circulars A-102 and A-1 10
\end{tabular}




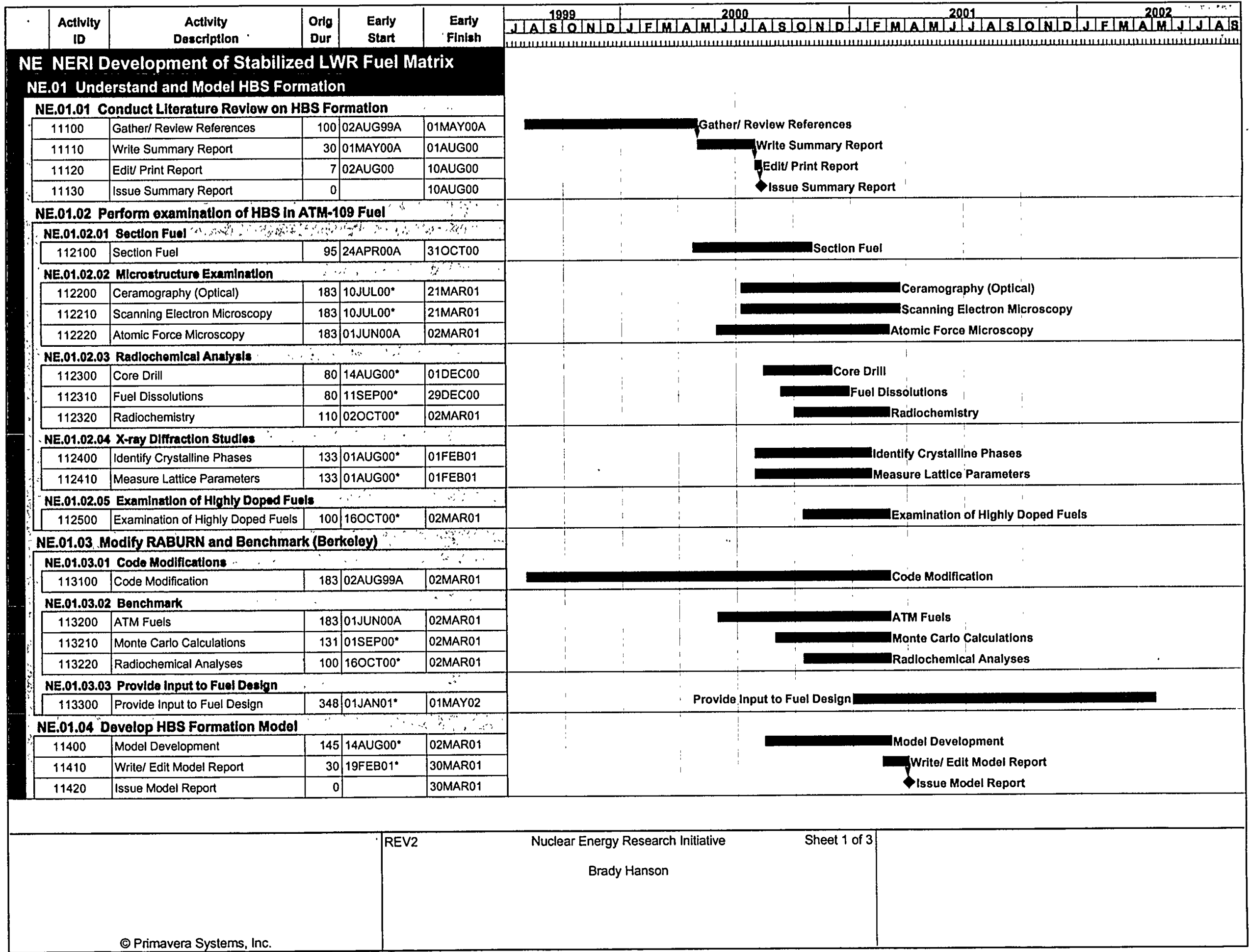




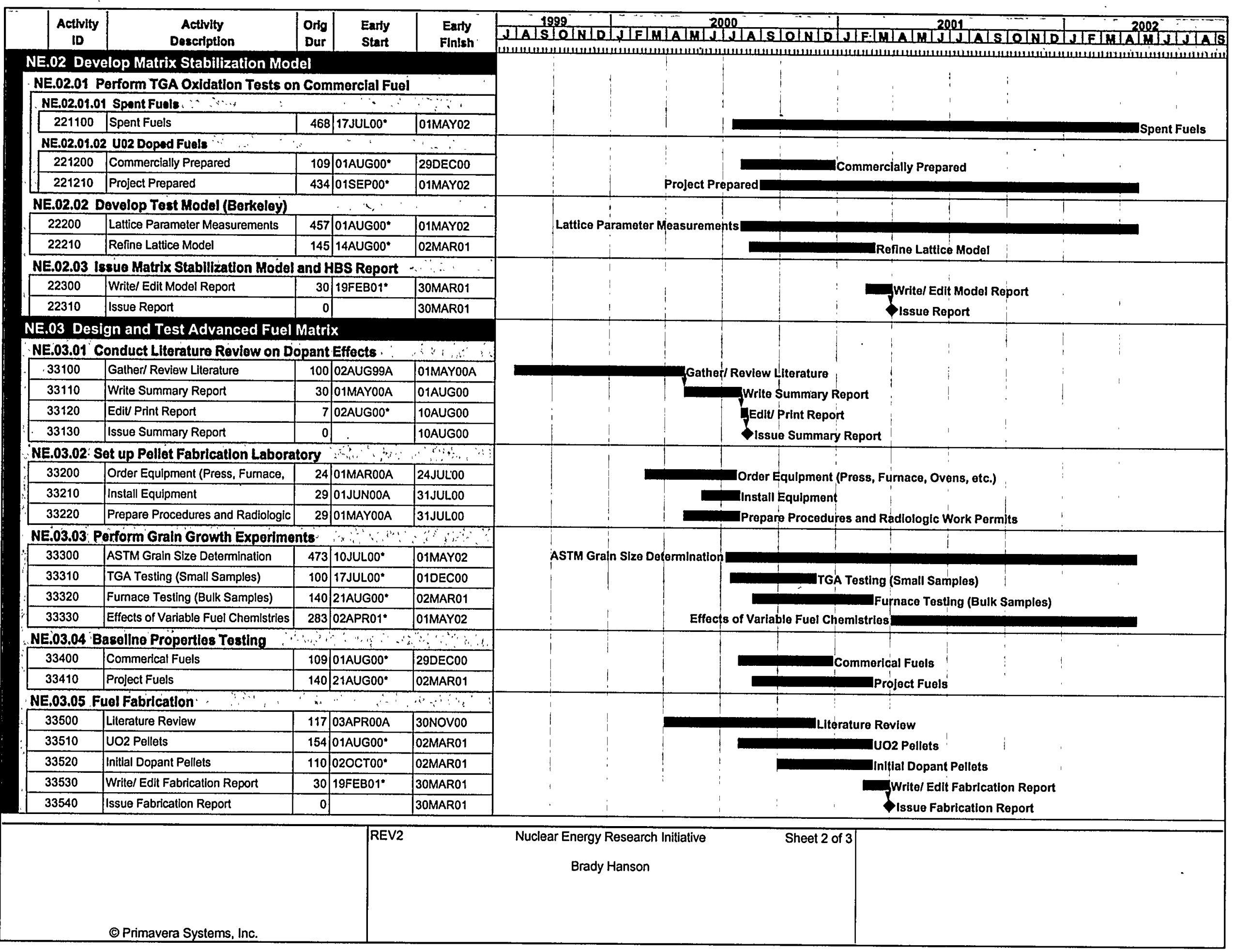




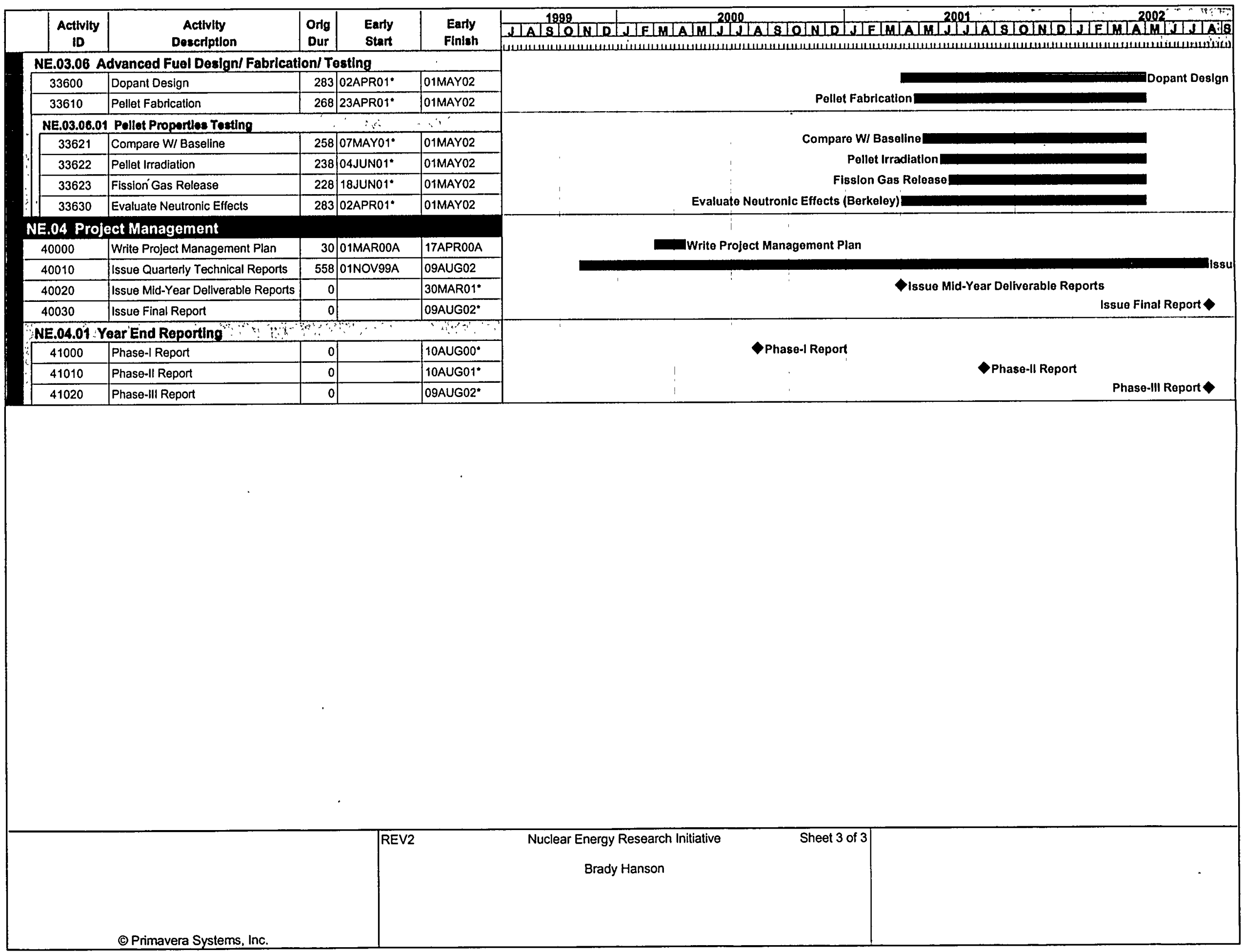




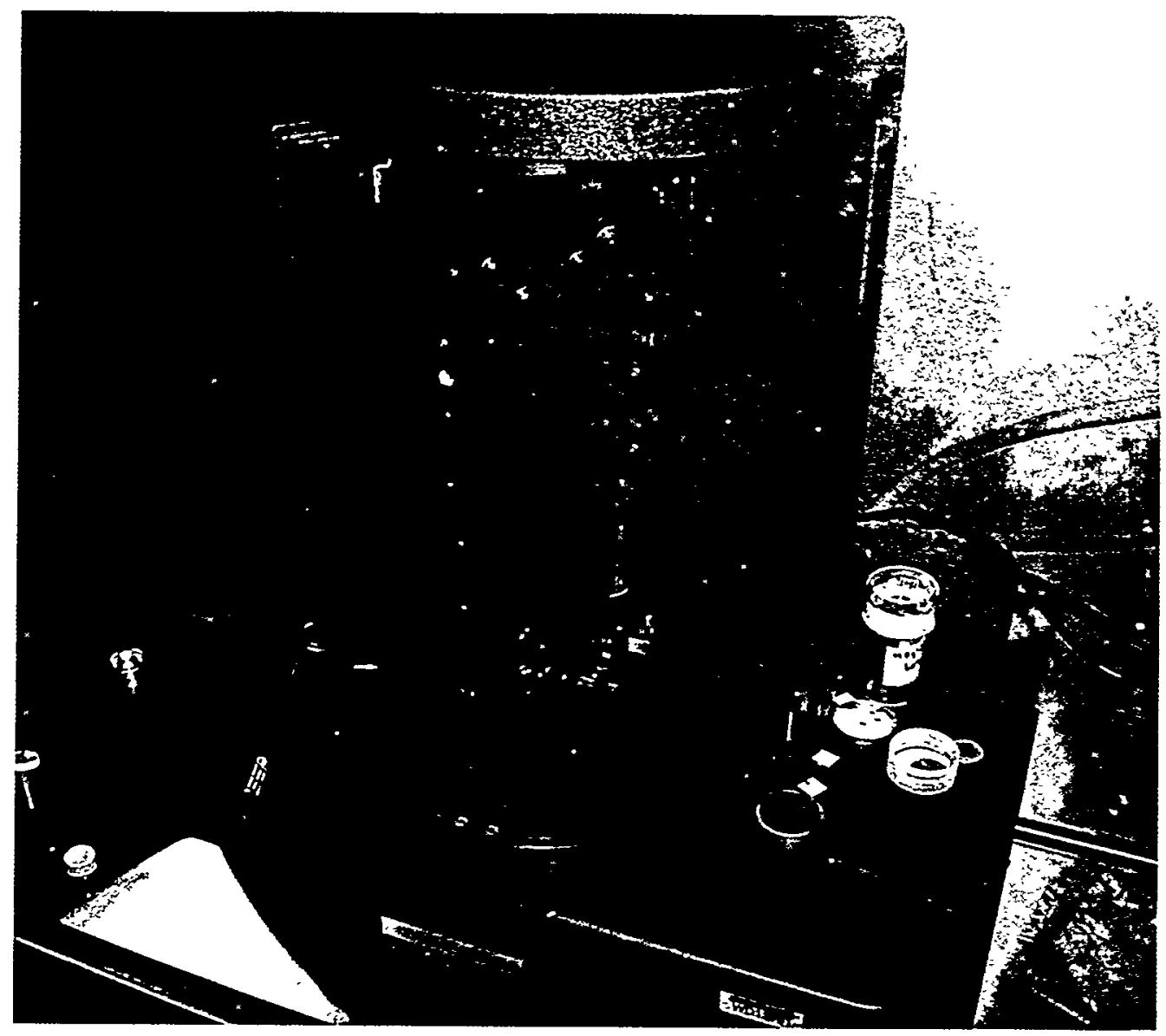

Figure 1. Photograph of the Park Scientific Instruments Autoprobe LS Atomic Force Microscope in a Shielded Glovebox at PNNL

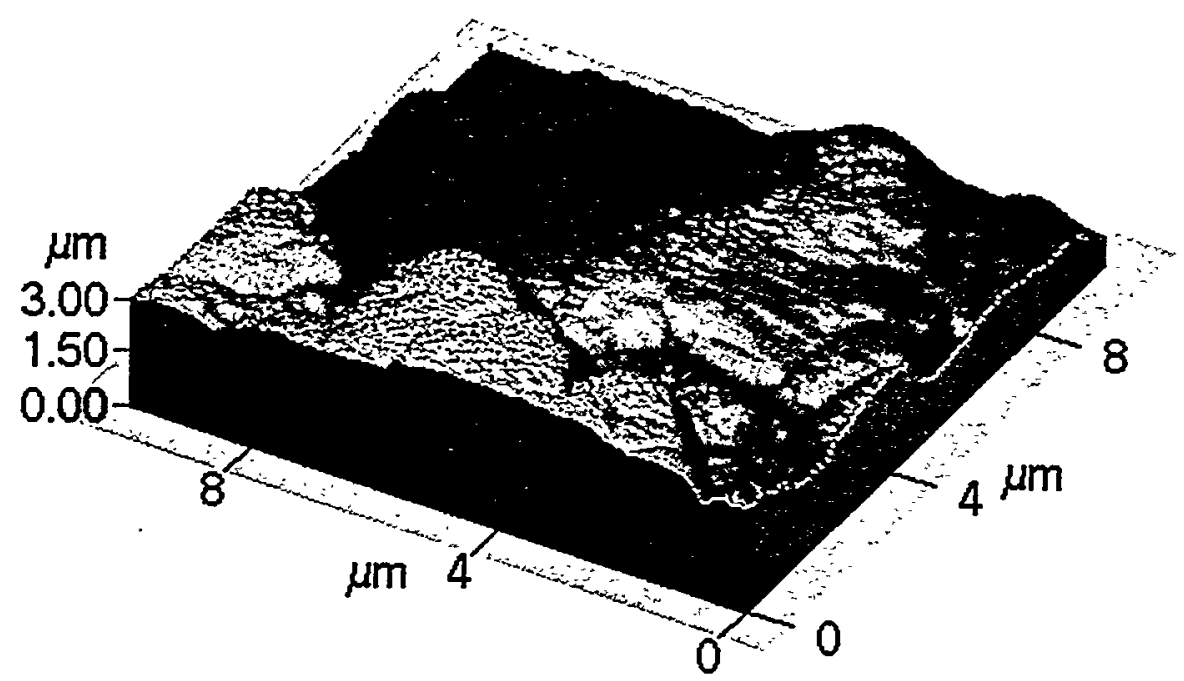

Figure 2. AFM Image of Unirradiated $\mathrm{UO}_{2}$ Showing the Grain Structure 


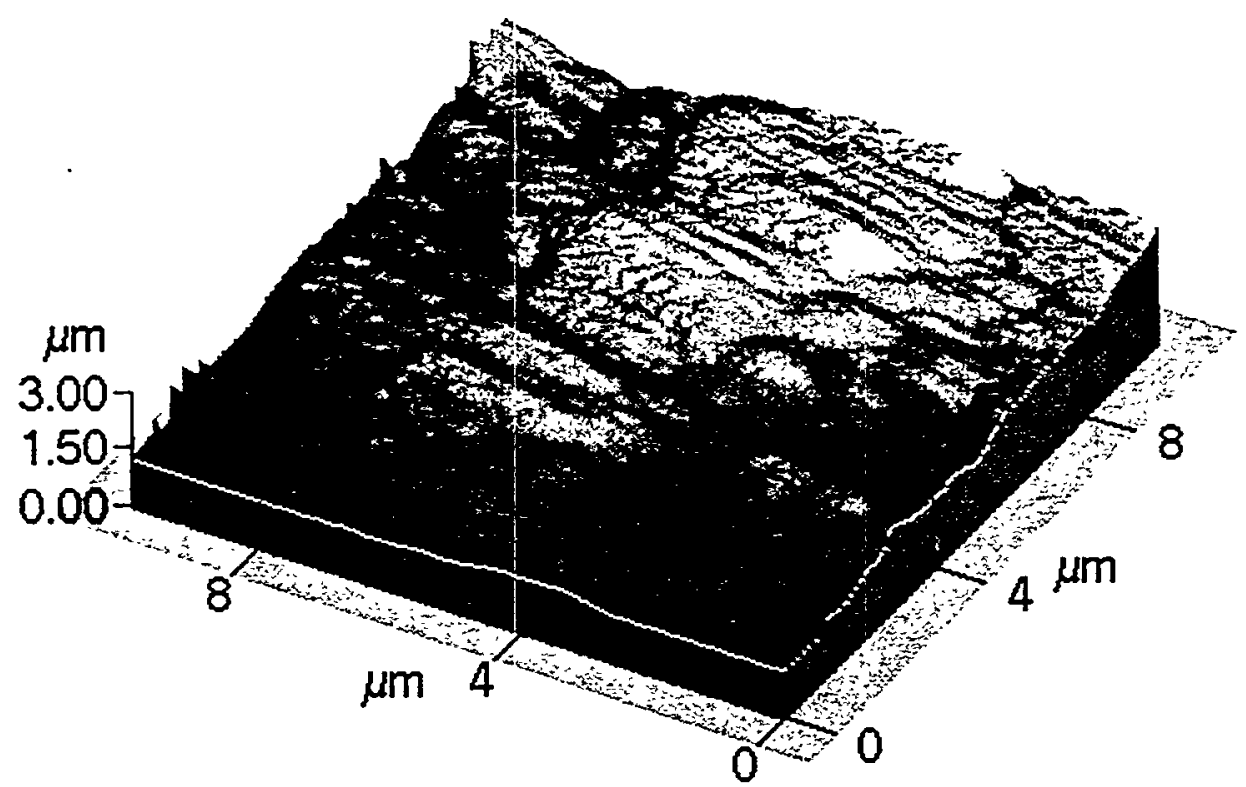

Figure 3. AFM Image of LWR Spent Fuel Away From the Restructured Zone

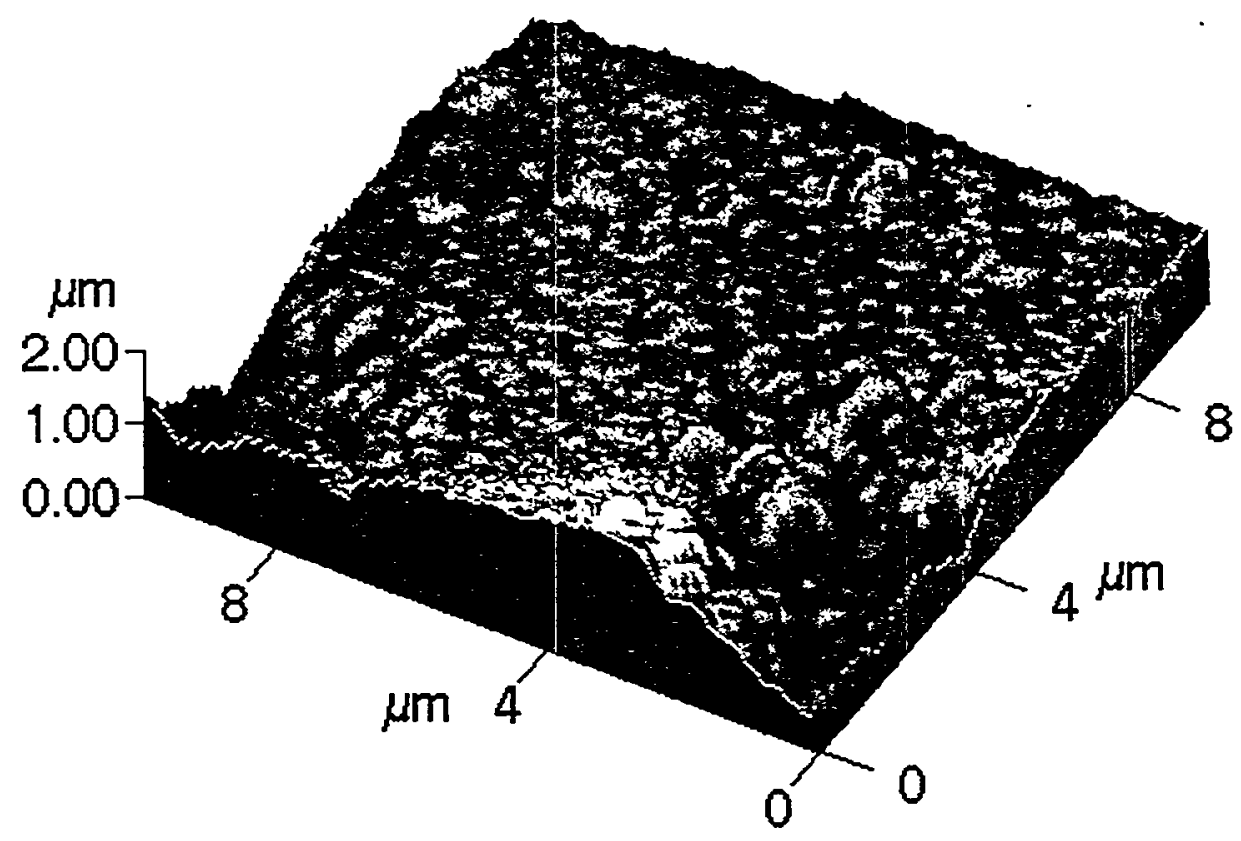

Figure 4. AFM Image of LWR Spent Fuel in the Restructured Zone 


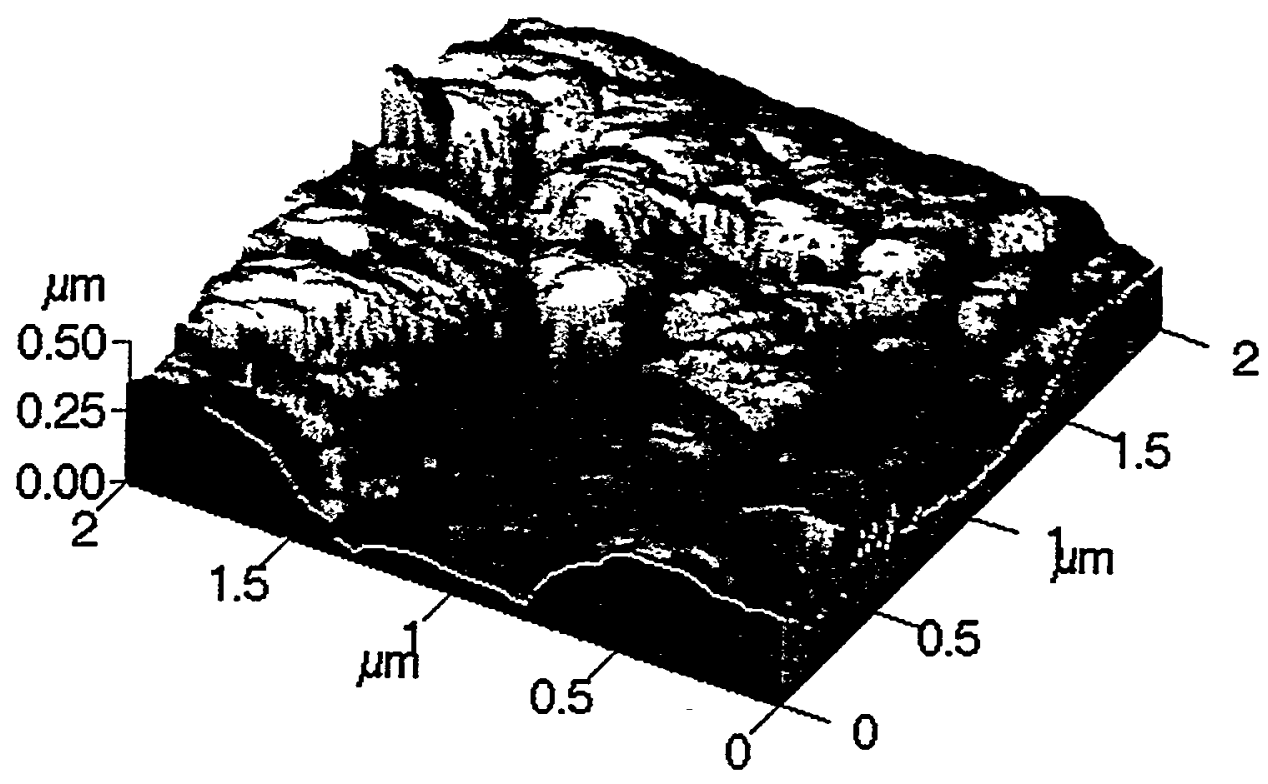

Figure 5. AFM Image at Higher Resolution Showing Restructured Grains

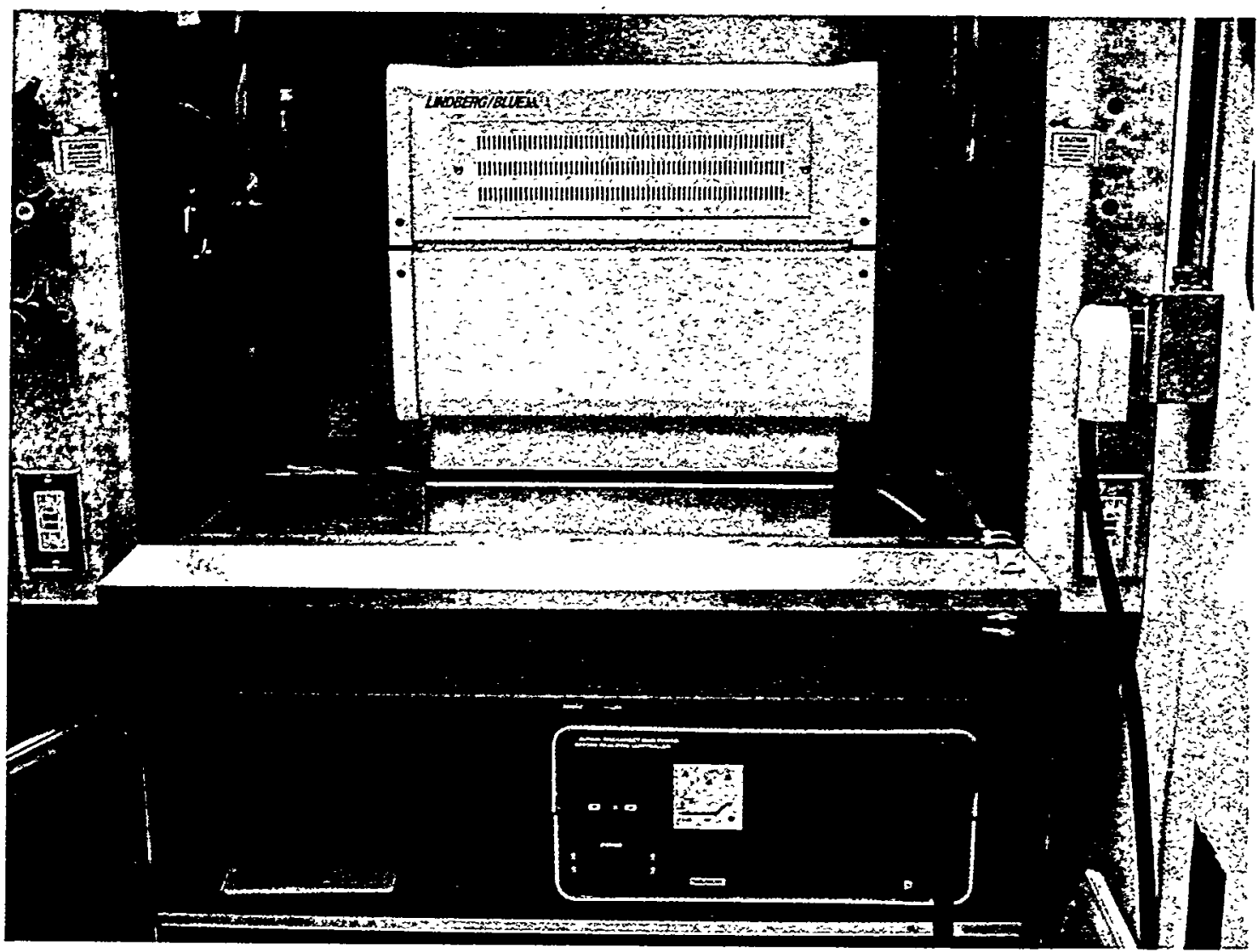

Figure 6. $1700^{\circ} \mathrm{C}$ Tube Furnace for Grain Growth and Sintering Experiments 


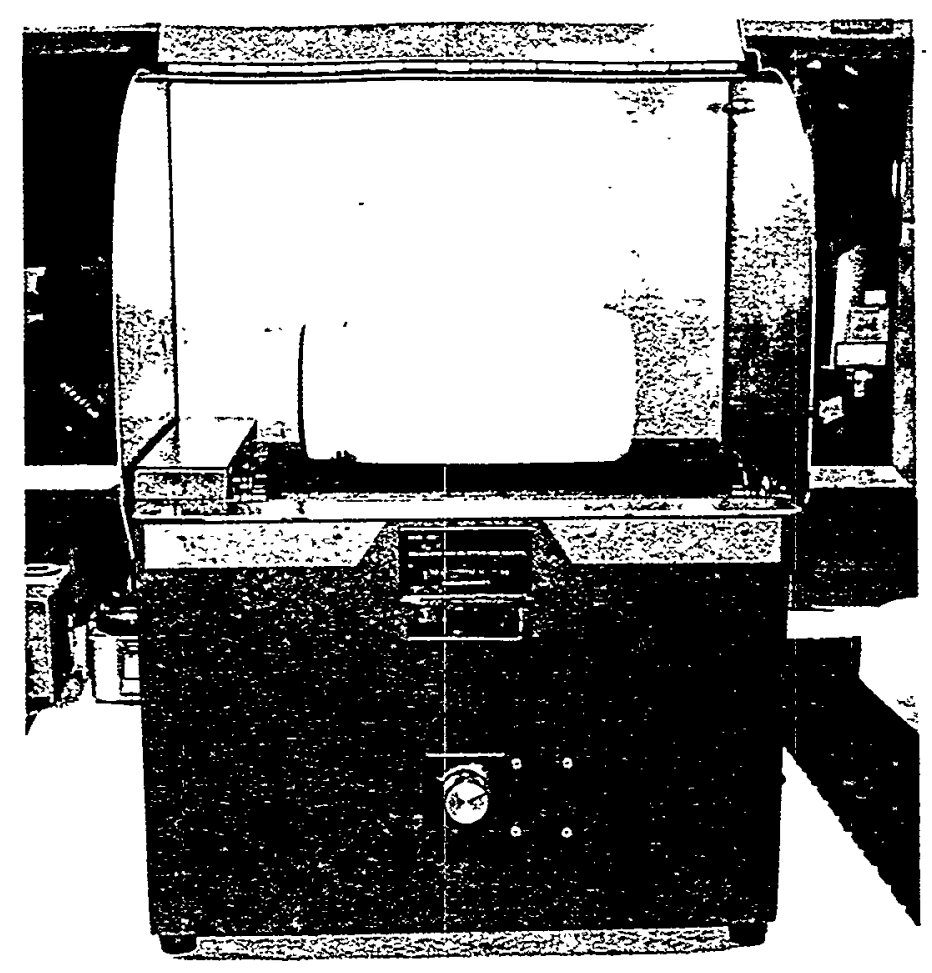

Figure 7. Jar Mill for Mixing and Homogenizing Samples

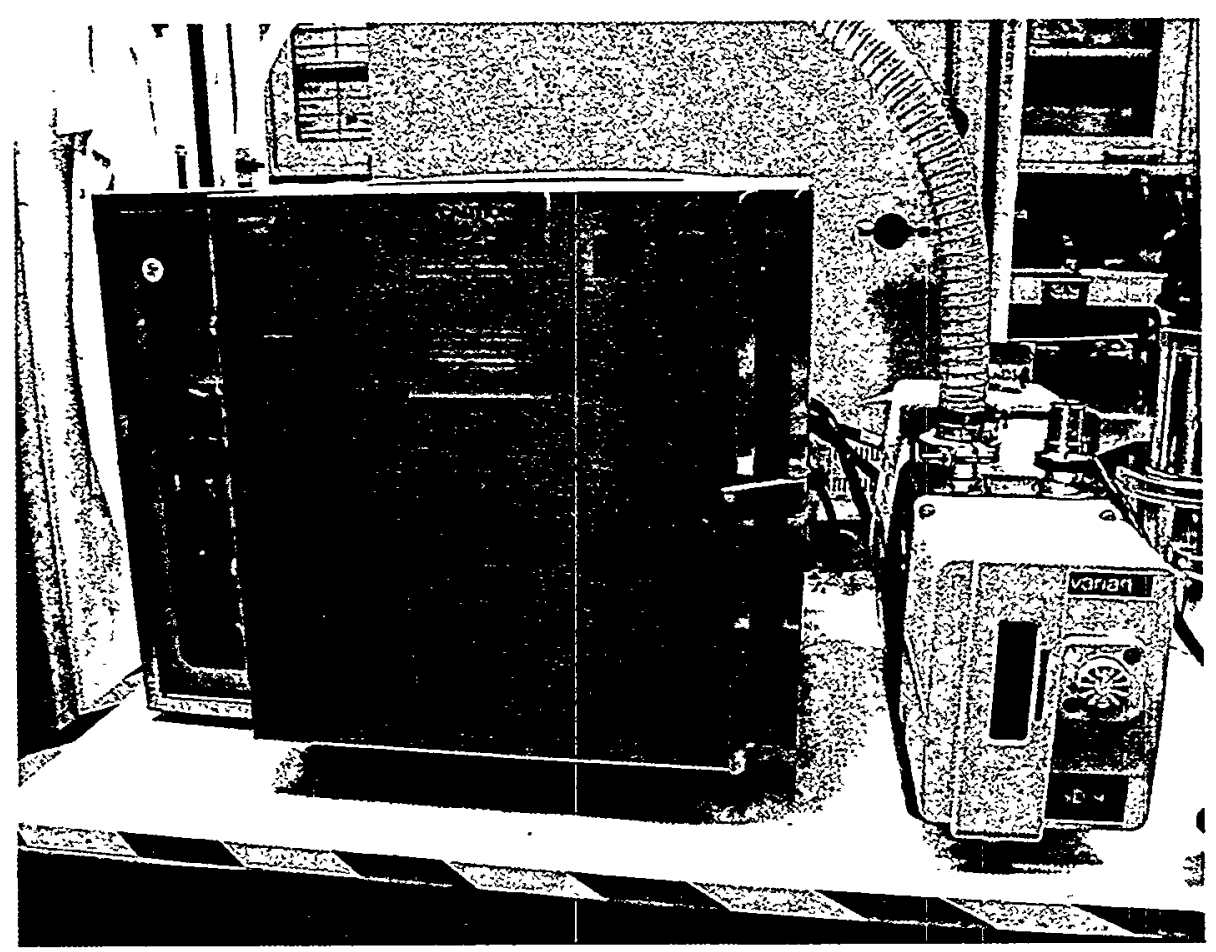

Figure 8. Vacuum Oven for Drying Samples 


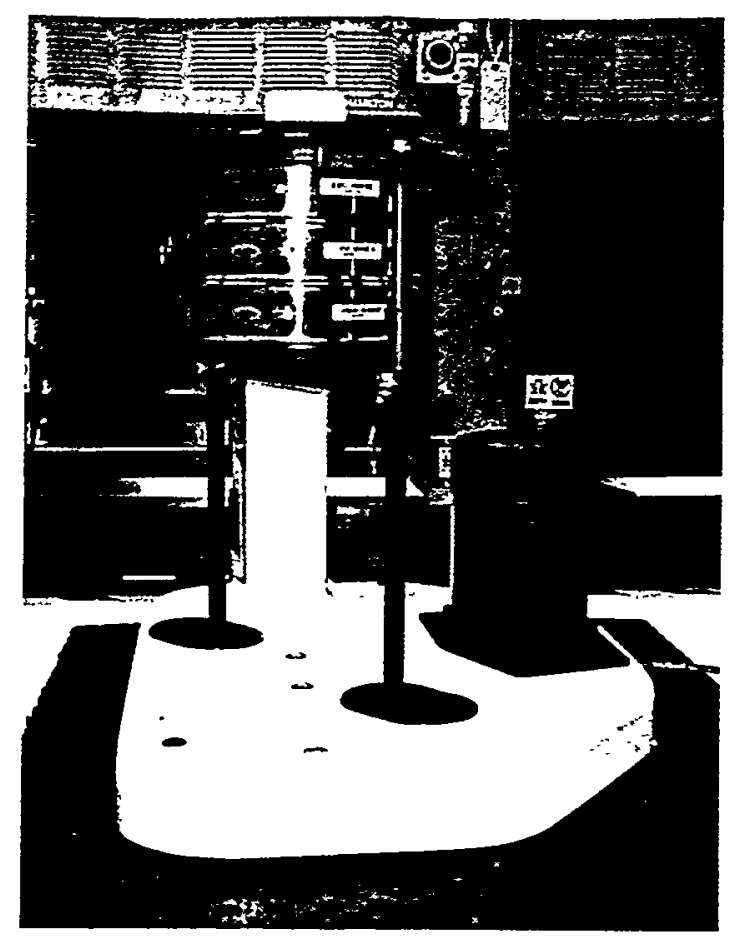

Figure 9. Mechanical Shaker for Sieving Samples

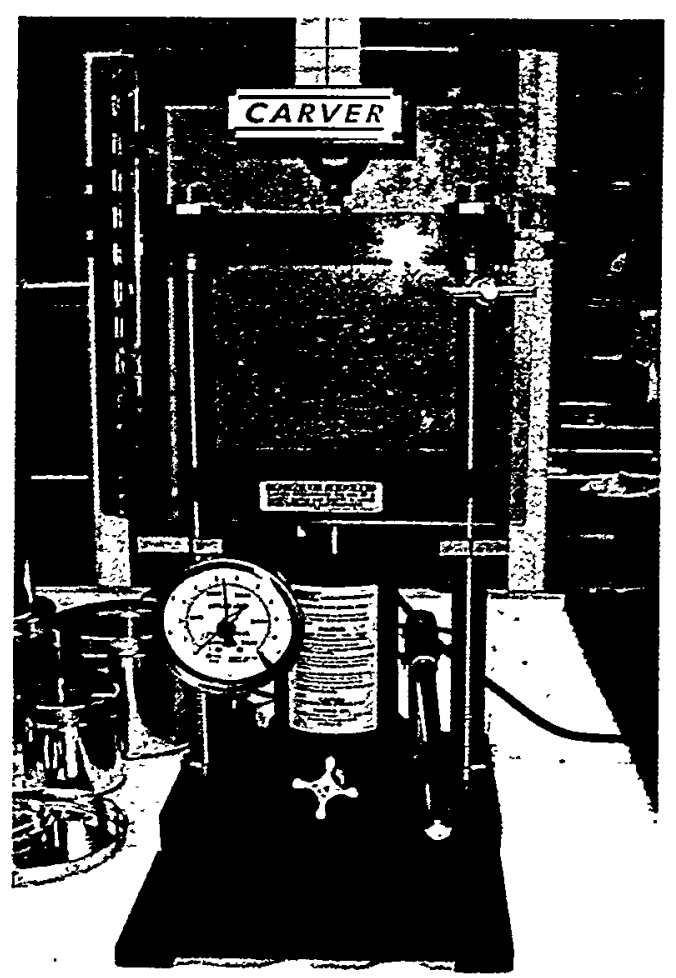

Figure 10. Pellet Press 


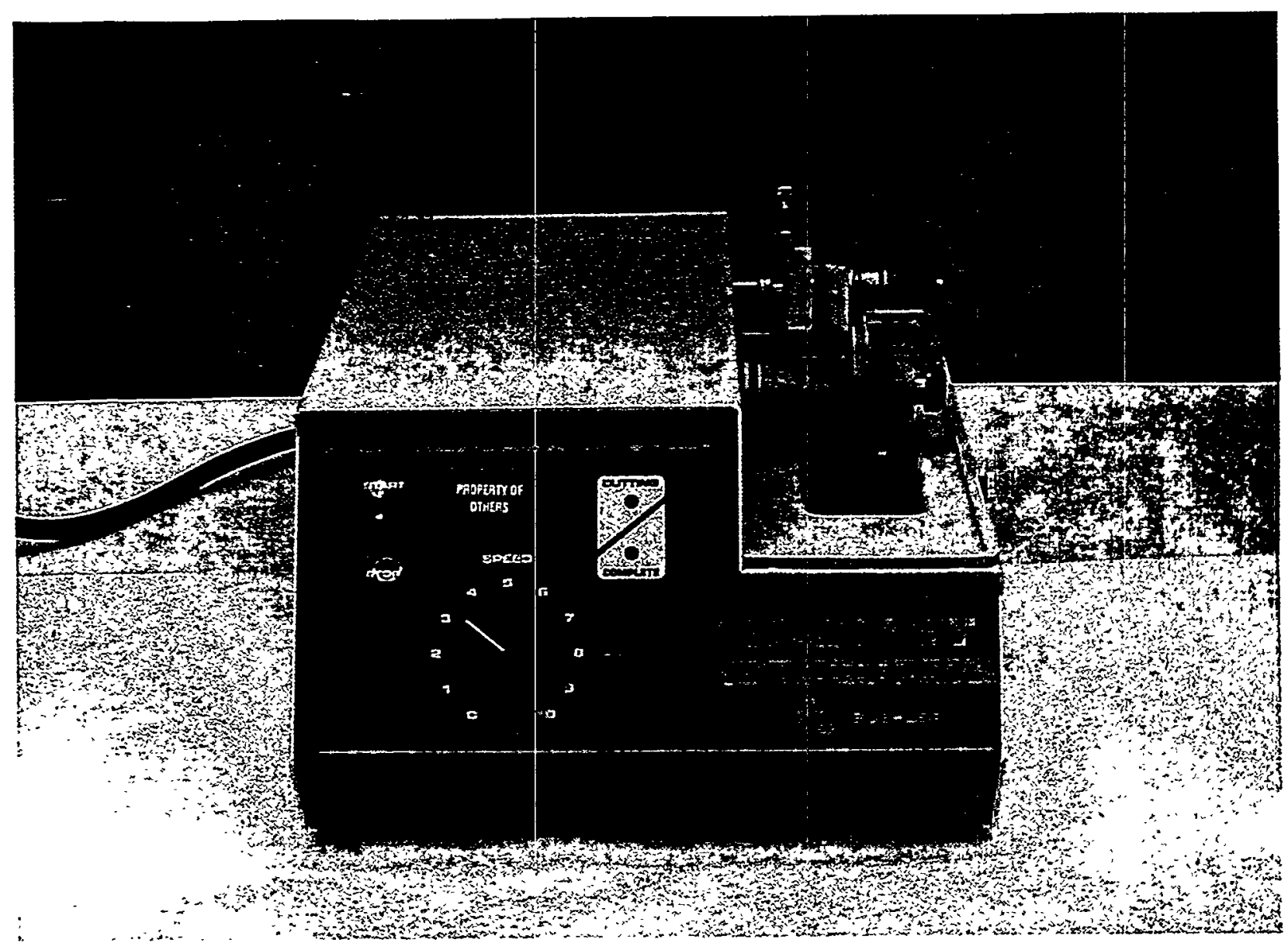

Figure 11. Low Speed ISOMET'M Saw for Sectioning Samples for Analysis 